\title{
Predicting Role of Social Support and Academic Stress on Life Satisfaction among Malaysian Adolescents
}

\author{
Siti Nor Yaacoba, Sophia Foo Mei Yee ${ }^{b}$, Gan Su Wanc \\ a Family, Adolescent and Child Research Center of Excellence (FACE), Department of Human Development and Family Studies, University Putra Malaysia, \\ 43400 Serdang, Selangor, Malaysia \\ ${ }^{b}$ Department of Human Development and Family Studies, University Putra Malaysia, 43400 Serdang, Selangor, Malaysia \\ 'Department of Psychology and Counseling, Universiti Tunku Abdul Rahman, 31900 Kampar, Perak, Malaysia
}

*Corresponding author: sitinor@upm.edu.my

\begin{abstract}
This paper aimed to examine the predicting role of social support (family and friends) and academic stress on life satisfaction among adolescents in Malaysia. A total of 359 secondary school students (mean of age $=16.26 ; 133$ male adolescents, 37.0\%) in Selangor were selected with cluster sampling method. Self-administrated questionnaires with existing established measurements were used for collecting response. Prior to conducting regression analysis, Pearson correlation analysis was ran for testing the relationship between social support (family and friends), academic stress and life satisfaction. Results showed that both social support from family $(\mathrm{r}=.433, \mathrm{p}<.01)$ and social support from friends $(\mathrm{r}=.483$, $\mathrm{p}<.01)$ had significant positive relationship with life satisfaction. On the other hand, academic stress $(r=-.011, p>.05)$ was failed to significantly related to life satisfaction. Thus, only social support from friends and family were included in regression analysis. By controlled respondents' background, social support from friends $(\beta=0.382$, $\mathrm{p}<0.001)$ and social support from family $(\beta=0.297, \mathrm{p}<0.001)$ were found to be the predictors of adolescents' life satisfaction. By interpreting the unstandardized beta values, social support from friends contributed higher predicting effect on adolescents' life satisfaction as compared with social support from family. In order to increase life satisfaction among adolescents, intervention should focus on the social support that provided by both family members and friends.
\end{abstract}

Keywords: Social support, family, friends, academic stress, life satisfaction

(C) 2017 Penerbit UTM Press. All rights reserved

\subsection{INTRODUCTION}

Life satisfaction refers to feelings and attitudes of an individual towards his or her life at a certain stages in life; which can exist in negative or positive form (Diener, 1984). It encompasses individual's perception on his or her life, desire to change life, satisfaction with his or her past attainments, and optimistic view of the future. Life satisfaction is an important component for well-being and mental health in aspects of personal, behavioral, psychological, and social outcomes (Proctor et al., 2009). Past studies reported that high level of life satisfaction functioned as a moderator against the impact of stressful life event in the development of psychopathology (Suldo \& Huebner, 2004). Theoretically, adolescents who are dissatisfied with life tend to cope poorly with stress, and consequently they may involve in substance abuse, sexual acts and even suicide attempts (Kim \& Kim, 2008). Renwick, Brown and Nagler (1996) found that life satisfaction is related to suicidal ideation and suicidal attitudes among adolescents. In other word, life satisfaction promotes adolescents' mental health, emotional well-being and school success (Lewis, 2010; Tamini \& Kahrazei, 2010). Life satisfaction is also an important variable in understanding the relationship between adolescents' experiences and both their adaptive or maladaptive behaviors (Huebner, Suldo, \& Gilman, 2006).

During adolescence, changes in cognitive, physiological, mental and social aspects occurred simultaneously (Simmons \& Blyth, 1987). The increased in self-esteem and self-consciousness among adolescents lead them to emphasize more on the importance of satisfaction on self and self-worth (Boden, Fergusson, \& Horwood, 2008). Adolescents who had higher satisfaction in life also tend to perceive higher social self-competence than those with low life satisfaction (Suldo \& Huebner, 2004). Individual's life satisfaction was constructed by his or her chosen criteria for quality of life and also the perception towards life goals. Adolescents who are developing own identity and forming close relationship tend to emphasize the quality of social relationship and also set academic achievement as a life goal. In addition, Huebner (1994) also discussed that life satisfaction is established through various environments which include self, family, peers, academic, and living environment. Thus, the present study examined friends support, family support, and academic stress as the predictors of life satisfaction among adolescents.

Supports from family and friends played a vital role in predicting life satisfaction among adolescents. Social support is defined as interpersonal relationships and supports provided by social institutions that affect individual's well-being (Costello, Pickens, \& Fenton, 2001). Social support from family and friends is important in contributing to positive psychological health of adolescents. Adolescents' perceptions of social support from family or peers contribute positively to their developmental outcomes. However, adolescents tend to perceive social support differently in the nature of relationship with family and friends (Procidano \& Hellen, 2000). Thus, it is necessary to test the effect of these two types of social support in predicting the level of life satisfaction among adolescents. 
The concept of Attachment Theory (Bowlby, 1969) is often used as a guide to examine the relationship between individual with their parents and friends (Nickerson \& Nagle, 2005). Secure base established during interaction with parents and friends helped adolescents to develop abilities required in facing stressful event and life challenges. With an increased in age, adolescents are not only rely on their parents, but prefer to seek companionship from peers. Apparently, as they mature, adolescents will integrate peer behaviors into their internal behavior (Crowell \& Waters, 1994). In this manner, interactions with both parents and peers might be inter-related in generalizing working model of adolescents (Kerns, Klepac, \& Cole, 1996). Supportive behavior includes affection from others which is a component of attachment. Therefore, this study aimed to examine how support from family and friends explain life satisfaction of adolescents.

Family is the closest social environment for adolescents. The dramatic changes in family life events would bring high impact on adolescents. For example, parents who spent less time with their children may have fewer communications with children, and provide lower level of social support and supervision during this critical period in development. The importance of positive parent-child relationships or parental support on adolescents' life satisfaction had been highlighted within Asian society due to high emphasis on family values (Leung, Wong, Wong, \& McBride, 2010). In the collectivism society, parents play their role as adults and supporter to develop positive developmental outcomes for their adolescent child. Past study found that parental support is linked to higher life satisfaction in adolescents; parent attachment also had positive relationship with life satisfaction (Leung et al., 2010). Moreover, parental acceptance and support were positively related to psychosocial adjustment among adolescents (Khaleque \& Rohner, 2002). Adolescents who established higher positive relationship with their family were found to have higher life satisfaction (Gilman \& Huebner, 2006).

The importance of support from friends had also been reported in several studies. Other than family support, adolescents also need appropriate support from peers in order to face various life challenges. During adolescence, positive relationship with friends is essential to increase adolescents' sense of belonging within the social circle; in which might influence their life satisfaction. Past study showed that adolescent who are securely attached to their peers was found to have higher quality of life (Green, Forehand, Beck, \& Vosk, 1980). Prior study also revealed that adolescents who perceived higher support from classmates tend to have higher level of life satisfaction (Suldo \& Huebner, 2004). A study by Nickerson and Nagle (2004) also confirmed that life satisfaction of adolescents is predicted by peer attachment. A study by Gilman and Huebner (2006) also revealed that the positive relationship between adolescents and friends contributed to higher life satisfaction. With social support from friends, adolescents are believed to be more confident and capable in handling obstacles and feel satisfied with current life situation.

During adolescence, adolescents spend more time at school than at home. Schools provide a diversity of developmental resources for students. It is a place where unique norms, values and culture are learned and practiced by the students (Crosnoe \& Lopez-Gonzalez, 2005). The culture that includes emphasis on academic competence contributes as a significant social context that will bring enormous effect on life satisfaction, especially for adolescents. Students' perception on their academic competence is highly affected by their academic performance (such as grades) and feedback (such as verbal compliments and criticisms) from their school's teachers (Valeski \& Stipek, 2001). How they perceived their academic competence might lead to academic stress that determines adolescents' life satisfaction. Academic stress is defined as the mental stress in respect to some anticipated frustration or awareness that is associated with academic failure (Gupta \& Khan, 1987). Academic stressors such as excessive homework, examinations, time management issues, and competition among classmates are considered as common stressors among students (Cheng, Leong, \& Geist, 1993). The study by Larue and Herman (2008) found that adolescents perceived school as the top contributor of stress in their lives. Stress may pose severe negative consequences on student's ability to perform, progress, or succeed in school, which consequently affect their perception on their life. Based on the literatures reviewed, students' academic stress may significantly influence their life satisfaction.

This study aimed to examine the predicting role of social support from family and friends, and academic stress on life satisfaction among adolescents in Selangor, Malaysia. Based on the reviews, this study hypothesized that: 1) social support from family and friends will link positively to life satisfaction, 2) Academic stress will relate negatively to life satisfaction, and 3) social support from family and friends, and academic stress will significantly predict life satisfaction.

\subsection{CONCEPTUAL FRAMEWORK}

Figure 1 showed the conceptual framework of the study on the relationships between social support from family and friends, academic stress and life satisfaction among adolescents. The antecedent variables were the respondents' family context. Independent variables were social support from family and friends, and academic stress while the dependent variable was life satisfaction.

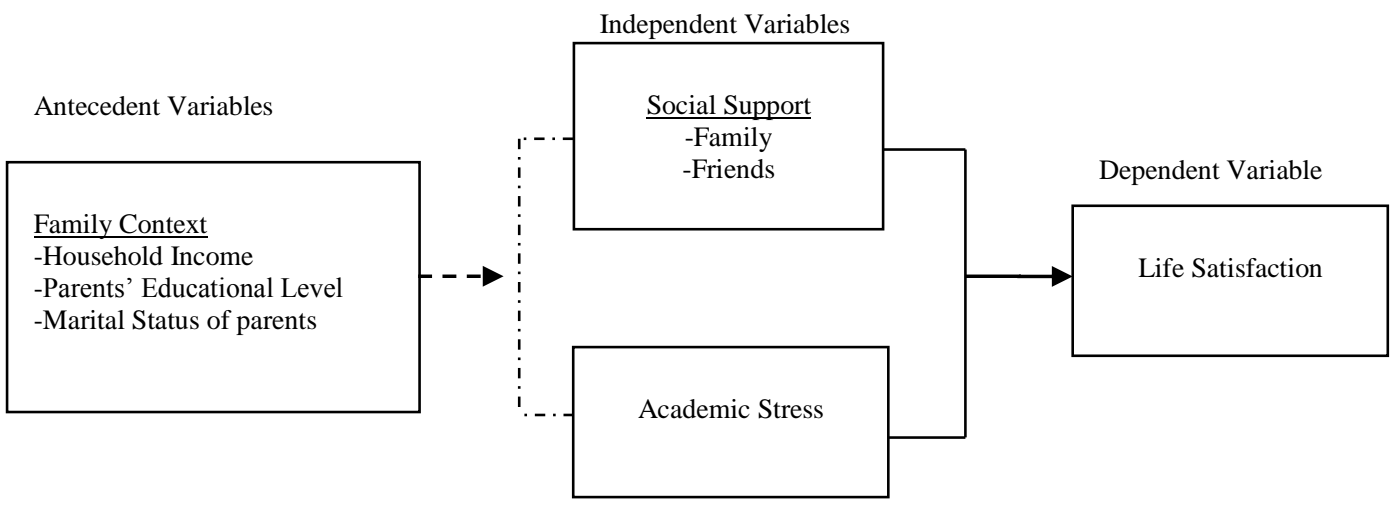

Figure 1 Conceptual framework for the study on relationship between social support, academic stress and life satisfaction among adolescents in Selangor, Malaysia. 


\subsection{METHODOLOGY}

\section{Design and Location of the Study}

This present study is quantitative and cross-sectional in nature, utilizing a correlational research design. This study examined the relationships between social support (family and friends), academic stress and life satisfaction among adolescents in Selangor. It was conducted in selected secondary schools in Selangor. Selangor was chosen as the location of study based on a report which indicated that Selangor was in the top five states with high percentage of suicidal cases in Malaysia (National Suicide Registry Malaysia, 2011). The life satisfaction of adolescents might be an important factor in building a positive mental health among adolescents, which might in turn prevent them from committing suicide in the future.

\section{Participants and Sampling Technique}

A total of 359 secondary school students in Selangor were selected as respondents in this study. The respondents were identified using cluster sampling method. The respondents consisted of $133(37.0 \%)$ males and $226(63.0 \%)$ females, aged between 13 and 17 years old $($ mean $=16.26, \mathrm{SD}=.85)$. Most of the respondents were Malay $(\mathrm{n}=167,46.5 \%)$, followed by Chinese $(\mathrm{n}=160,44.6 \%)$, Indian $(\mathrm{n}=28$, $77.8 \%)$, and other races $(n=4,1.1 \%)$. A total of $325(90.5 \%)$ respondents reported that their parents were married couple. Respondents were from families with mean monthly income RM 4506.12 ( $\mathrm{SD}=3661.53$ ). Majority of the respondents' parents had at "Sijil Pelajaran Malaysia" qualification (Malaysia Certificate of Education).

\section{Research Instrument}

Social Support from family and friends. The Multidimensional Scale of Perceived Social Support (MSPSS) (Dahlem et al., 1991) was used to measure how one perceives their social support from family and friends. The MSPSS has two subscales which are social support from family and social support from friends. Example of the item for social support from family is "I can talk about my problem with my family". Example of the item for social support from friends is "I can count on my friends when things go wrong". Respondents are required to respond the items by using a 7-point scale ( $1=$ "Very Strongly Disagree" to 7 = "Very Strongly Agree"). Each subscale has four items. The total score for each subscale is from 4 to 28 . Higher score indicate a higher perceived social support from family or friends by respondents. The Cronbach alpha value for social support from family and social support from friends are 0.84 and 0.82 respectively.

Academic Stress. The 16-items of Educational Stress Scale for Adolescents (ESSA) (Ang \& Huan, 2006) was used to assess the academic stress of adolescents. The ESSA contains five dimensions which are pressure from study (example: I feel a lot of pressure in my daily studying.), workload (example: I feel there is too much homework), worry about grades (example: I am very dissatisfied with my academic grades), self-expectation (example: I always lack confidence with my academic scores), and despondency (example: I feel stress when I do not live up to my own standards). Each item was rated with a 5-point Likert scale ranging from 1 (Strongly disagree) to 5 (Strongly agree). The lowest score of the scale was 16 while the highest possible score was 80 . Higher score represents higher academic stress faced by respondents. The Cronbach alpha value for this instrument in the current study is 0.80 .

Life satisfaction. The 18-items of Multidimensional Students' Life Satisfaction Scale (MSLSS) (Huebner, 1994; Sawatzky et al., 2009) was used to measure five aspects of adolescents' life satisfaction which are living environment, school, family, friends, and self-life satisfaction. Examples for family, friends, school, living environment and self-life satisfaction items are "My parents treat me fairly", "I have a lot of fun with my friends", "I look forward to going to school", "I like where I live", and "There are lots of things I can do well" respectively. Respondents were required to respond on their thoughts on life experiences during the past several weeks. Six-point response scale from $1=$ strongly disagree to $6=$ strongly agree, was used to rate each item. Total score was computed with high score indicating high level of overall and specific domains of life satisfaction. The possible scale score for the MSLSS is between 18 and 108 . The Cronbach alpha value for the MSLSS in the present study is 0.87.

\section{Data Collection}

Data were collected using self-administered questionnaires which were distributed to the selected respondents in the school setting. Permission to conduct the study was obtained from the Ministry of Education, Department of Education of Selangor, and principles from each selected school. Respondents were briefed on the research purpose, the confidentiality of the data, and informed consent. The questionnaires were collected immediately after the respondents had completed it.

\section{Data Analysis}

Data of this study were analyzed by Predictive Analytics Software (PASW) version 20. Descriptive analyses were run to describe the respondents' background and the main study variables. Prior to regression analysis, Pearson correlation analysis was conducted to analyze the relationship between social support from family and friends, academic stress and life satisfaction. All the independent variables that were significantly related to life satisfaction were included in the regression model to determine the unique predictor of life satisfaction among adolescents. 


\subsection{RESULTS AND DISCUSSION}

\section{Univariate Analysis}

Table 1 showed the distribution of respondents by categories of study variables. It was categorized into three categories which are low, medium and high level. Respondents attained average 20.13 marks for Social support from family in Multidimensional Scale of Perceived Social Support (MSPSS). The lowest score is 4 and highest score is 28. Higher score indicated higher perceived social support from family. More than $50 \%$ of the respondents $(n=199,55.4 \%)$ were in the high level of family support, followed by medium level $(n=143$, $39.9 \%)$ and only 17 respondents $(4.7 \%)$ perceived low level of social support from family.

The results also showed that respondents obtained higher mean scores on social support from friends (20.72) in Multidimensional Scale of Perceived Social Support (same number of items with family subscales) than the mean scores of family subscale (20.13). In addition, the lowest scores of social support from friends is 8 and highest scores is 28 . Most of the respondents were in the medium level of social support from friends $(n=175,48.7 \%)$, followed by high level $(n=150,41.8 \%)$ and low level $(n=34,9.5 \%)$ of peer support.

As shown in Table 1, the minimum score of academic stress is 33 while the maximum score is 78 . Majority of the respondents $(\mathrm{n}=$ $232,64.6 \%$ ) reported medium level of academic stress. Similar number of respondents was distributed into the low and high level of academic stress whereby 72 respondents $(20.1 \%)$ perceived high level of academic stress and 55 respondents (15.3\%) scored low level of academic stress.

According to Table 1, the minimum score of life satisfaction was reported as 41 while the maximum score was 106 . Majority of the respondents were in the medium $(n=166,46.2 \%)$ and high level $(n=163,45.4 \%)$ categories of life satisfaction. Only 30 respondents $(8.4 \%)$ perceived low satisfaction towards their life. As reviewed, adolescents' life satisfaction is dependent on social support from family and friends. Since most of the respondents reported medium to high level of social support from family and friends, it implied that most of them are experiencing quality social life and in turn perceived high level of life satisfaction. Other than the total score, sub-domains of life satisfaction were also analyzed. Mean score for respondents' life satisfaction with family, school, self, friends and living environment is 4.72, 4.29, 4.26, 4.79 and 4.41 respectively. Amongst the domains, respondents obtained better mean scores in life satisfaction with family and friends. Majority of the respondents perceived high level of satisfaction with family, school, friends and living environment, except for satisfaction on self.

Table 1 Distribution of respondents by category of main study variables

\section{Variable}

Social support from family

Low (4-11)

Medium (12-19)

High (20-28)

Social support from friends

Low (8-15)

Medium (16-21)

High (22-28)

Academic stress

Low (33-48)

Medium (49-63)

High (64-78)

Life satisfaction

Low (41-63)

Medium (64-84)

High (85-106)

Domains of life satisfaction

Family

Low (1.50-3.00)

Medium (3.01-4.50)

High (4.50-6.00)

School

Low (1.25-2.83)

Medium (2.84-4.42)

High (4.43-6.00) $\mathbf{n}(\%)$

$17(4.7)$

$143(39.9)$

199 (55.4)

\section{Mi}

4

Max

28

Mean

20.13

SD

4.94

34 (9.5)

175 (48.7)

150 (41.8)

33

78

56.47

8.38

55 (15.3)

232 (64.6)

72 (20.1)

41

106

81.07

12.73

$30(8.4)$

166 (46.2)

163 (45.4)

26 (7.2)

125 (34.9)

208 (57.9)

48 (13.4)

119 (33.1)

192 (53.5)
1.50

6.00

4.72

0.98

1.25

6.00

4.29

1.13
1.50

6.00

4.26

(continued)
.92 


\begin{tabular}{|c|c|c|c|c|c|}
\hline Low (1.50-3.00) & $39(10.9)$ & & & & \\
\hline Medium (3.01-4.50) & $192(53.4)$ & & & & \\
\hline High (4.50-6.00) & $128(35.7)$ & & & & \\
\hline Friends & & 1.00 & 6.00 & 4.79 & .96 \\
\hline Low (1.00-2.67) & $10(2.8)$ & & & & \\
\hline Medium (2.68-4.34) & $92(25.6)$ & & & & \\
\hline High (4.35-6.00) & 257 (71.6) & & & & \\
\hline Living environment & & 1.00 & 6.00 & 4.41 & 1.22 \\
\hline Low (1.00-2.67) & $34(9.5)$ & & & & \\
\hline Medium (2.68-4.34) & $113(31.4)$ & & & & \\
\hline High (4.35-6.00) & $212(59.1)$ & & & & \\
\hline
\end{tabular}

\section{Correlation Analysis between Variables}

Table 2 displays the results of correlation analysis between social support from family and friends, academic stress and life satisfaction. Results showed that social support from family and friends were correlated with each other $(\mathrm{r}=.358$, $\mathrm{p}<.001)$. Social support from family $(\mathrm{r}=.433, \mathrm{p}<.001)$ had significant positive correlation with life satisfaction. Results indicated that higher level of social support from family leads to higher level of life satisfaction or vice versa. The result is consistent with the past research (Young, Miller, Norton, \& Hill, 2004) which found that adolescents who perceived parental support tend to experience higher level of life satisfaction. Meanwhile, Pearson correlation results also revealed that there was a positive relationship between social support from friends and life satisfaction $(\mathrm{r}=$ $.485, \mathrm{p}<.001)$. It denoted that respondents who perceived high social support from friends reported to have high level of life satisfaction. Consistently, Suldo and Huebner (2004) reported that adolescents who perceived high support from classmates had high level of life satisfaction. Peer attachment had also been found to significantly predict life satisfaction among adolescents (Nickerson \& Nagle, 2004). Academic stress did not relate significantly to life satisfaction among adolescents. Past study found that life satisfaction of adolescents is significantly linked to their academic outcomes (Suldo, Shaffer, \& Riley, 2008). This contradicting result might be due to the different academic expectations or perception of respondents across nation and culture.

Table 2 Correlation analysis between the variables $(\mathrm{N}=359)$

\begin{tabular}{|c|c|c|c|c|}
\hline Variable & $\mathbf{1}$ & 2 & 3 & 4 \\
\hline 1. Social support from family & - & - & - & - \\
\hline 2. Social support from friends & $.358 * * *$ & - & - & - \\
\hline 3. Academic stress & -.054 & $.115^{*}$ & - & - \\
\hline 4. Life satisfaction & $.433 * * *$ & $.483^{* * *}$ & -.011 & - \\
\hline
\end{tabular}

Predicting Role of Social Support from Family and Friends on Adolescents' Life Satisfaction

Table 3 showed the results of hierarchical regression analysis in predicting life satisfaction of adolescents. In Step 1, marital status of parents, educational level of parents, and household income were entered into the analysis as the control variables. In Step 2, social support from family and social support from friends were entered into the hierarchical regression model. Total variance explained by the Model 2 as a whole was $30.9 \%[\mathrm{~F}(6,352)=27.678]$. Higher $\beta$-value indicated stronger predictor of variable. The results showed that after controlling marital status of parents, educational level of father and mother, and household income, social support from friends $(\beta=0.382$, $\mathrm{p}<.001)$ appeared to be the strongest predictor for life satisfaction, followed by social support from family $(\beta=0.297$, $p<.001)$. Results revealed that respondents with high social support from family and friends also reported higher life satisfaction. 
Table 3 Predicting effect of social support from family and friends on adolescents' life satisfaction

\begin{tabular}{lcccccc}
\hline \multicolumn{1}{c}{ Variables } & & Step 1 & & \multicolumn{3}{c}{ Step 2 } \\
Step 1 & B & SE.B & Beta, $\boldsymbol{\beta}$ & B & SE.B & Beta, $\boldsymbol{\beta}$ \\
\hline Marital status & .552 & 1.606 & .020 & 1.729 & 1.340 & .062 \\
Father's education level & .412 & .380 & .067 & .164 & .317 & .027 \\
Mother's education level & -.030 & .403 & -.004 & -.377 & .336 & -.056 \\
Household income & .000 & .000 & .079 & .000 & .000 & .069
\end{tabular}

(continued)

\begin{tabular}{|c|c|c|c|c|}
\hline \multicolumn{5}{|l|}{ Step 2} \\
\hline Social support from family & & .764 & .122 & $.297^{* * *}$ \\
\hline Social support from friends & & 1.146 & .142 & $.382 * * *$ \\
\hline $\mathrm{R}^{2}$ & .013 & & .321 & \\
\hline Adjusted $\mathrm{R}^{2}$ & .001 & & .309 & \\
\hline$F$ value & 1.122 & & 27.678 & \\
\hline
\end{tabular}

The findings of this study strengthened previous study (Gilman \& Huebner, 2006) which found that adolescents with high global life satisfaction scores reported having more positive relationships with their peers and parents. Although both social support from family and friends were found to be significant predictors of life satisfaction of adolescents, social support from friends seems to be a stronger predictor. By applying the attachment theory, the results of the correlation and regression analysis can be explained. Attachment theory discussed the role of parents and friends in individual's life (Nickerson \& Nagle, 2005). During this developmental stage, even though adolescents are still dependent on their parents; they also seek and expand their relationship with others, especially peers. Adolescents spend the longer time with their schoolmates and friends because they found similarities with their friends. Therefore, they may share their feelings and problems with their peer group. Adolescents also often think that their friends were able to understand them better compared to their family members. Therefore, they tend to seek more support from their friends. Thus, social support from friends appeared to be the strongest variable which uniquely predicted life satisfaction.

\subsection{CONCLUSION}

Based on the findings of this study, academic stress of respondents showed no significant correlation with their life satisfaction. Perceived social support from significant others may buffer adolescents from stress. By perceived high level of social support from family and friends, respondents might be more capable to cope with academic stress. When they face academic related problems, they can seek for assistance and guidance from family members and friends. It implied that academic stress might be indirectly link to life satisfaction of adolescents.

Finding of this study indicated that social supports from both friends and family were the significant predictors of adolescents' life satisfaction. It is important for adolescents to obtain sufficient social support from their family and friends as they are the closest person to them and spend longer time with them. Thus, supportive behavior from family and friends boosted adolescents' satisfaction with life. Specifically, the results indicated that social support from friends was the strongest unique predictor of life satisfaction of respondents, followed by social support from family. During adolescence, peer support is very important as they spend most of the time in schools and they are more willing to share their problems with their friends as compared to parents. According to Hartup (1996), depression and negative self-views of adolescents was caused by the low quality of peer relationship which included lack of close friends and rejected by friends. Adolescents with low social support from friends might be isolated and discriminated by friends which cause them to encounter low self-esteem and become more pessimistic. This will eventually lead them to perceive low level of satisfaction in life. Therefore, social support from friends played a crucial role in adolescents' life which leads them to be more satisfied life.

\subsection{IMPLICATIONS AND SUGGESTION FOR FUTURE STUDY}

The findings of the present study highlighted the importance of social support from family and friends in contributing to life satisfaction among adolescents. Thus, intervention should focus on adolescents' interaction between family members and peers. In order to increase social support from family, program that requires involvement of family members and adolescents should be organized by relevant parties. This provides opportunities to gather all family members together and strengthen their bonding via different activities. In addition, schools or non-profit organization can also organize more workshops targeting at parents and family members that includes topics like current issue on communication, conflict resolution and discussion on the current social problem of adolescents. In addition, social and interactive program which involved participation of adolescents can be organized to increase social support from friends. For example, Sports Day, and after-school programs can be held to increase their sense of belonging to the social group. 
The current study utilized a correlational research design and it is cross-sectional in nature with limited sample and geographical location. Therefore, it may limit generalizability of the findings. In order to increase the generalizability of the findings within Malaysia context, future study can randomly select respondents from other states in Malaysia.

\section{References}

Ang, R. P., \& Huan, V. S. (2006). Academic expectations stress inventory (AESI): Development, Factor Analysis, Reliability And Validity. Educational and Psychological Measurement, 66, 522-539.

Armsden, G. C., \& Greenberg, M. T. (1987). The Inventory Of Parent And Peer Attachment: Relationships To Well-Being In Adolescence. Journal of Youth and Adolescence, 16, $427-454$

Boden, J. M., Fergusson, D. M., \& Horwood, L. J. (2008). Does Adolescent Self-Esteem Predict Later Life Outcomes? A Test Of The Causal Role Of Self-Esteem. Development and Psychopathology, 20,319-339.

Bowlby, J. (1969). Attachment and loss: Vol. 1. Attachment (2nd ed.). New York, NY: Basic Books

Cheng, D., Leong, F., \& Geist, R. (1993). Cultural Differences In Psychological Distress Between Asian and Caucasian American College Students. Journal of Multicultural Counseling and Development, 21(3), 182-189.

Costello, J., Pickens, L. M., \& Fenton, J. (2001). Social Support: A Matter Of Connections. Chicago, IL: Chapin Hall Center for Children at the University of Chicago.

Crosnoe, R., \& Elder, G. H. (2004). Family dynamics, supportive relationships, and educational resilience during adolescence. Journal of Family Issues, 25,571 602.

Crowell, J., \& Waters, E. (1994). Bowlby‘s Theory Grown Up: The Role Of Attachment In Adult Love Relations. Psychological Inquiry: An International Journal of Peer Commentary and Review, 5, $31-34$

Dahlem, N. W., Zimet, G. D., \& Walker, R. R. (1991). The Multidimensional Scale of Perceived Social Support: A Confirmation Study. Journal of Clinical Psychology, 47, 756-761.

Diener, E. (1984). Subjective Well-Being. Psychological Bulletin, 95, 542-575.

Gilman, R., \& Huebner, E. S. (2006). Characteristics of Adolescents Who Report Very High Life Satisfaction. Journal of Youth and Adolescence, 35(3), $311-319$.

Green, K. D., Forehand, R., Beck, S. J., \& Vosk, B. (1980). An Assessment Of The Relationship Among Measures Of Children'S Social Competence And Children`S Academic Achievement. Child Development, 51, 1149- 1156.

Gupta, K., \& Khan, B. (1987). Anxiety Levels As Factors In Concept Formation. Indian Journal of Psychological Report, 31, 187-192.

Hartup, W. W. (1996). The Company They Keep: Friendships And Their Developmental Significance. Child Development, 67, 1-13.

Huebner, E. S. (1994). Preliminary Development And Validation Of A Multidimensional Life Satisfaction Scale. Psychological Assessment, 6, $149-58$.

Huebner, E. S., Suldo, S. M., \& Gilman, R. (2006). Life Satisfaction. In G. Bear \& K. Minke (Eds.), Children's Needs III: Development, Prevention, And Correction, 357 - 368. Bethesda, MD: NASP.

Kerns, K. A., Klepac, L., \& Cole, A. K. (1996). Peer Relationships And Preadolescents‘ Perceptions Of Security In The Mother-Child Relationship. Developmental Psychology, 32, $457-466$

Kim, H. S., \& Kim, H. S. (2008). Risk Factors For Suicide Attempts Among Korean Adolescents. Child Psychiatry and Human Development, $39,221-235$.

Larson, R., \& Ham, M. (1993). Stress And - Stress And Storm In Early Adolescence: The Relationship Of Negative Events With Dysphoric Affect. Development Psychology,29, 130-140.

Larue, D., \& Herrman, J. W. (2008). Adolescent Stress Through The Eyes Of High Risk Teens. Pediatric Nursing, 34, 375-380.

Leung, A. N. M., Wong, S. S. F., Wong, I. W. Y., \& McBride, C. (2010). Filial Piety And Psychosocial Adjustment In Hong Kong Chinese Early Adolescents. Journal of Early Adolescence, 30, 651-667.

Lewis, A. D. (2010). Facilitating Student Engagement: The Importance Of Life Satisfaction. PhD Diss., University of South Carolina.

Nickerson, A. B., \& Nagle, R. J. (2004). The Influence Of Parent And Peer Attachments On Life Satisfaction In Middle Childhood And Early Adolescence. Social Indicators Research, 66(1-2), 35-60.

Nickerson, A. B., \& Nagle, R. J. (2004). The Influence Of Parent And Peer Attachments On Life Satisfaction In Middle Childhood And Early Adolescence. Social Indicators Research, 66(1-2), 35-60.

Proctor, C. L., Linley, P. A., \& Maltby, J. (2009). Youth Life Satisfaction: A Review Of The Literature. Journal of Happiness Studies, 10, 583-630.

Renwick, R., \& Brown, I. (1996). Being, Belonging, Becoming: The Centre For Health Promotion Model Of Quality Of Life. In R. Renwick, I. Brown, \& M. Nagler (eds), Quality of Life In Health Promotion And Rehabilitation: Conceptual Approaches, Issues, And Applications, 139-250. Thousand Oaks, CA: Sage

Sawatzky, R., Ratner, P. A., Johnson, Joy. L., Kopec, J. A., \& Zumbo, B. D. (2009). Sample Heterogeneity And The Measurement Structure Of The Multidimensional Students“ Life Satisfaction Scale. Social Indicator Research, 94, 273-296.

Simmons, R. G., \& Blyth, D. A. (1987). Moving into Adolescence: The Impact Of Pubertal Change And School Context. Hawthorne, NJ: Aldine.

Suldo, S. M., \& Huebner, E. S. (2004). Does Life Satisfaction Moderate The Effects Of Stressful Life Events On Psychopathological Behavior During Adolescence? School Psychology Quarterly, 19(2), 93-106.

Suldo, S. M., Shaffer, E. S., and Riley, K. (2008). A Social-Cognitive-Behavioral Model Of Academic Predictors Of Adolescents' Life Satisfaction. School Psychology Quarterly, 23, 56-69.

Tamini, B. K., \& Kahrazei, F. (2010). General Health And Life Satisfaction Of Students In Polygamy And Monogamy Families. Journal of the Indian Academy Applied Psychology, 36, 307-10.

Valeski, T. N., \& Stipek, D. (2001). Young Children's Feelings About School. Child Development ,73, 1198-2013.

Young, M. H., Miller, B. C., Norton, M. C., \& Hill, E. J. (1995). The Effect Of Parental Supportive Behaviors On Life Satisfaction Of Adolescent Offspring. Journal of Marriage and Family, 57, 813-822. 